\title{
Fathers' Involvement in the Care of Their Infants and Their Attributions of Cognitive Competence to Infants
}

\author{
Anat Ninio; Nurith Rinott \\ Child Development, Vol. 59, No. 3. (Jun., 1988), pp. 652-663.
}

Stable URL:

http://links.jstor.org/sici?sici=0009-3920\%28198806\%2959\%3A3\%3C652\%3AFIITCO\%3E2.0.CO\%3B2-\%23

Child Development is currently published by Society for Research in Child Development.

Your use of the JSTOR archive indicates your acceptance of JSTOR's Terms and Conditions of Use, available at http://www.jstor.org/about/terms.html. JSTOR's Terms and Conditions of Use provides, in part, that unless you have obtained prior permission, you may not download an entire issue of a journal or multiple copies of articles, and you may use content in the JSTOR archive only for your personal, non-commercial use.

Please contact the publisher regarding any further use of this work. Publisher contact information may be obtained at http://www.jstor.org/journals/srcd.html.

Each copy of any part of a JSTOR transmission must contain the same copyright notice that appears on the screen or printed page of such transmission.

The JSTOR Archive is a trusted digital repository providing for long-term preservation and access to leading academic journals and scholarly literature from around the world. The Archive is supported by libraries, scholarly societies, publishers, and foundations. It is an initiative of JSTOR, a not-for-profit organization with a mission to help the scholarly community take advantage of advances in technology. For more information regarding JSTOR, please contact support@jstor.org. 


\title{
Fathers' Involvement in the Care of Their Infants and Their Attributions of Cognitive Competence to Infants
}

\author{
Anat Ninio and Nurith Rinott
}

The Hebrew University of Jerusalem

\begin{abstract}
Ninio, ANAT, and RinOTT, NuRITH. Fathers' Involvement in the Care of Their Infants and Their Attributions of Cognitive Competence to Infants. ChIld Development, 1988, 59, 652-663. The relation between fathers' involvement in the care of their infants and their attributions of cognitivesocial skills to infants was investigated in this study. 160 pairs of parents of 9 -month-old infants were interviewed. On the average, fathers were available to their infants 2.75 hours per weekday and spent 45-50 min interacting with them. They performed 1 caretaking activity per day, and took sole responsibility for the infant only about once in 10 days. Results indicate that fathers who are less involved in child care attribute lesser competence to infants than relatively more involved fathers, that fathers in general attribute lesser competence to infants than mothers, and that the more involved a father is in infant care, the less differençe there is between his attributions and those of his wife's. These results raise the possibility that involvement in care and perception of infants as cognitively competent are mutually reinforcing.
\end{abstract}

It is well known that fathers, on the whole, are much less involved in infant care than mothers, be it in terms of responsibility, availability, time spent in interaction, or performance of caretaking activities (e.g., Baruch \& Barnett, 1984; Kotelchuck, 1976; Pleck, 1983; Riley, 1985). According to some estimates, the average father spends as little as 15-25 min a day interacting with his infant (Ban \& Lewis, 1974; Pleck, 1982), whereas mothers, even if employed outside the house, seldom spend less than an hour (e.g., Pleck, 1982).

Even though it seems promising to hypothesize that such quantitative differences in exposure to the infant are associated with qualitative differences in the two parents' knowledge of, and beliefs about, the infant's skills and capacities, the issue has received scant attention in the literature. Except for studies dealing with parents of retarded children, whose case is obviously atypical (see Wolfensbuerger \& Kurtz, 1971, for a review), the only study comparing mothers' and fathers' beliefs about the expected developmental levels of young children was carried out by Clarke-Stewart (1978). Although Clarke-Stewart did not find significant differences between mothers' and fathers' developmental expectations regarding their 30 - month-old children, the findings are not easily generalized because her sample consisted of only 14 pairs of parents. Absence of studies of this issue is unfortunate because such parental cognitions could well be important in determining parental behavior. For instance, it has been found that fathers tend to engage less often than mothers in verbal, didactic, toy-mediated play with their infants (Jackson, 1980; Lamb, 1976; Parke \& Tinsley, 1981; Russell, 1979). It could well be that fathers' avoidance of this type of play stems from their relative unfamiliarity with the infant: It is necessary to be fairly familiar with an infant's current skills and range of interests in order to successfully engage him or her in activities of this "intellectual" type. Indeed, microanalyses of parent-infant play revealed that fathers are less effective than mothers in eliciting appropriate play behaviors from the infants (Power, 1985). Fathers prefer physical, rough-and-tumble, and idiosyncratic nonstereotyped play, which requires much less "fine-tuning" to the infant's current cognitive attainments. It may also be that fathers tend to underestimate the infants' needs for, and capacities to engage in, more complex, cognitively demanding activities.

The current study focused on the relation between fathers' involvement in infant care

This research was supported by grants from the Sturman Center for Human Development and the Faculty of Social Sciences of the Hebrew University of Jerusalem. The authors wish to thank Miriam Peyser who collected some of the data in partial fulfillment of her requirements for an M.A. in psychology. Requests for reprints should be sent to Anat Ninio, Department of Psychology, The Hebrew University, Jerusalem 91905, Israel.

[Child Development, 1988, 59, 652-663. () 1988 by the Society for Research in Child Development, Inc. All rights reserved. 0009-3920/88/5903-0004\$01.00] 
and their attributions of cognitive-social skills to infants to test the hypothesis that there exists a positive relation between amount of involvement and attribution of skills. Specifically, it was expected that fathers who are less involved in child care attribute lesser competence to infants than relatively more involved fathers, that fathers in general attribute lesser competence to infants than do mothers, and that the more involved a father is in infant care, the less difference there is between his attributions and those of his wife's.

Involvement with the infant was expected to result in the attribution of greater social-cognitive competence to infants because it provides the parent with opportunities to observe behaviors that indicate the infant's abilities as well as sensitize her or him to the sometimes subtle cues of their presence. A similar suggestion was made by Sagi and Reshef (1984) to account for the fact that highly involved fathers of 3-6-year-olds had greater expectations than did little-involved fathers regarding the age at which their children would attain independence and social maturity.

A positive relation between paternal involvement and attributions of competence can be expected on yet another ground: Fathers who attribute a greater measure of cognitive maturity to infants may be better motivated to be involved with their own child. These two hypotheses are complementary rather than conflicting in that a circular relation may be postulated to exist between beliefs and amount of interaction. Believing that infants are relatively complex and thus interesting persons may serve to enhance some fathers' readiness to take care of them and spend time in their company; actual exposure may reinforce these beliefs and vice versa.

In the current study, Israeli fathers' involvement with their 9-month-old infants was assessed in a relatively large urban Jewish sample, and the two parents' beliefs about the timetable of cognitive development in infancy were obtained. The choice of a sample homogeneous as to the infants' age was dictated by previous findings that fathers' involvement varies with the age of their children (see Pleck, 1982). The age of 9 months was chosen as representative of the middle period of infancy.

Testing the hypotheses of this study in a sample that included a wide range of demographic characteristics required consideration of the fact that both paternal involvement in infant care and beliefs about infants' cognitive skills appear to be influenced by the parents' cultural background. Fathers' involvement in child care is determined in part by the parents' sex role attitudes, and these, in turn, appear to vary according to the parents' ethnic origin and years of education. Israeli Jewish families from a non-Western cultural background (i.e., who emigrated from Moslem countries) are generally considered to be more patriarchal in values; in some studies they have been found to exhibit a more traditional (i.e., gender-specific) style of allocating family roles compared to families with a Western (i.e., European) background (BarYosef, 1969; Palgi, 1970). In addition, fathers' education or socioeconomic status has been shown to be positively predictive of their participation in the care of their infants in some studies (Masalcha, 1982; Riley, 1985; Russell, 1981, although for absence of such findings see Oakley, 1974; Russell, 1980, 1982, 1983). The same background variables have been shown to be related to attributions of cognitive skills to infants, at least in the case of mothers (Goodnow, Cashmore, Cotton, \& Knight, 1984; Ninio, 1979; Rosenthal, 1985): mothers of non-Western origin, and/or of lesser schooling and socioeconomic status, believe that infants acquire some basic cognitive skills at a later age than do their Western, educated counterparts. To assess the association between paternal involvement and beliefs independent of effects mediated by cultural background, demographic information was collected and the appropriate conditional analyses performed.

In line with views expressed by several authors (Lamb, Pleck, Charnov, \& Levine, 1985; Radin, 1982) we assumed that paternal involvement is a multidimensional phenomenon and that the use of a single, overall measure can be highly misleading. In the present study, two indices of time spent with the infant (availability and interaction) and two indices of caretaking responsibility (father's participation in caretaking activities and his being solely responsible for the infant) were used to estimate father's involvement in the daily life of his infant. Although interrelated, these aspects of involvement are sufficiently independent so that, for instance, they are differently related to family background (Baruch \& Barnett, 1984; Riley, 1985; Russell, 1981).

\section{Method}

\section{Subjects}

The sample consisted of 160 Jewish twoparent families with an infant aged 9 months 


\section{Child Development}

(range 8.7-9.7 months). The sample was drawn from the registrar of live births in Jerusalem, and it consisted of the first 160 families on the registrar for the relevant month who could be contacted and who agreed to participate in the study. Ultrareligious (i.e., Chasidic) families were not sampled.

The ethnic origin of the fathers included 45.1\% from Europe and America, and 54.9\% from Asia-North Africa; about half (49.4\%) were Israeli born. Of the mothers, $47.4 \%$ were from Europe-America, and 52.6\% were from Asia-North Africa; $53.1 \%$ were Israeli born. Mothers had an average of 12.6 years of education ( $\mathrm{SD}=3.0$ ); for fathers the average was 13.3 years $(\mathrm{SD}=3.6)$. The spouses' ethnic origin, birthplace, and years of schooling were highly congruent; the within-family correlations were $.69, .48$, and .74 , respectively. The proportion of mothers employed outside the home was $58.2 \%$; these worked an average of 5.5 days (SD $=1.3)-50 \%$ a full working day, and the others 5 hours or less a day. Mothers' mean age at delivery was 29.7 years $(\mathrm{SD}=5.8)$, fathers' 33.3 years $(\mathrm{SD}=6.5)$. The mean birth order of the target child was $2.6(\mathrm{SD}=1.6)$ with $26.9 \%$ being firstborns; $51.9 \%$ were girls. The average age gap between the target children and older siblings was 47.5 months $(\mathrm{SD}=33.0)$.

\section{Instruments and Procedure}

The extent of fathers' involvement with their infants was assessed by two methods. One consisted of interviewing the fathers to obtain their estimates of their daily availability, interaction time, caregiving, and responsibility over a period of 10 typical days. The validity of these estimates was cross-checked by having the fathers describe in chronological order all they did during the last 2 days, and extracting parallel estimates of daily involvement from these descriptions; this method was similar to the indirect questioning employed by Hoffman and Lippit (1960) and by Sigel, Hoffman, Dreyer, and Torgoff (1957). It was thought that, whereas factors such as memory limitations and social desirability may bias fathers' reports of their typical pattern of involvement, their detailed descriptions of time allocation could not be so biased unless they resorted to outright falsification. To avoid contamination, questioning concerning allocation of time was carried out first, without making it explicit that the focus of interest was on the father's contact with his infant.
The time-use interview. - The interviews were conducted in the evening. Fathers were asked to describe in detail everything they had done while they were home (or in the company of the infant outside their home) on the day of the interview and on the previous day. When a father's description was not detailed enough for our purposes, he was asked direct questions concerning $(a)$ the exact time he arrived home and/or left it, and the exact time the infant woke up and/or went to sleep; this was done so as to permit calculating the amount of time fathers were available for interaction with their infants; $(b)$ the exact type of interaction he was engaged in with the infant, given that the father reported that some kind of interaction (or "play") took place; this was to confirm that the two actually had interacted and not just spent time in each other's presence; and $(c)$ who fed, diapered, dressed, bathed, or put the infant to bed while the father was at home. The 2 days sampled were always weekdays (note that the weekend in Israel consists of only 1 day).

The questionnaire of estimated paternal involvement.-Upon completion of the interview, the fathers were given a questionnaire on which they were asked to estimate the amount of time they were available for their infant and the amount of time they spent interacting with the child on a typical weekday. If a father indicated that he had different work schedules on different days, he was asked to give estimates for each type of day and a weighed weekly average was calculated. Fathers were also asked to estimate the number of times in 10 days that they had performed various caretaking activities and took sole responsibility for the infant for more than 1 hour. For each typical context of caretaking (e.g., breakfast, lunch, dinner, naptime, bedtime, etc.) there were separate questions regarding the frequency at which the father participated in that form of care.

Estimates of paternal involvement.Two sets of scores on the following four measures of paternal involvement were computed; one set was based on the information from the interview and the other on the questionnaire.

1. Availability: the daily average amount of time the father is at home when the infant is awake (including time spent outside the house in the company of the infant).

2. Interaction: the daily average amount of time the father is engaged in active interaction with the infant, namely, taking care of, 
playing with, or being otherwise directly engaged with the infant.

3. Caretaking: the daily average number of times the father performs by himself the following caretaking activities: feeding (a whole meal, not just a snack), dressing or changing diapers, bathing (giving the infant a full bath), and putting the infant to bed. Regarding the last task, the interview-based measure reflects only 1 day's performance. The day of the interview was not taken into account here, because despite the late hour some infants were not yet in bed at the time of the interview. In scoring the questionnaire, a father who performed an activity less often than once in 10 days received a score of zero (nonparticipation) for that activity. The four task-specific scores were combined to create an overall caretaking score which summarizes the average number of major caretaking activities the father performs daily. There were roughly 10 major caretaking activities performed for an infant per day by all of the child's caretakers.

4. Sole responsibility: on the basis of the interview, the daily average amount of time the father reported to have spent alone with the infant was taken as a measure of his being solely responsible for the infant. The direct question used in the questionnaire referred to the number of times in 10 days the father was left as the sole caretaker of his infant for at least 1 hour. The daily average score was computed as this number divided by 10 , and it reflects the probability that on a particular day the father will be left alone with the infant for an hour or more.

Correlations between the estimates based on the interview and on the questionnaire were $r=.70$ for availability, $r=.77$ for interaction time, and $r=.61$ for overall caretaking. Among the specific caretaking acts, the correlations between the two sets of measures were moderately high for feeding (.59), dressing (.71), and bathing (.68) but very low for putting the infant to bed (.16). It seems that whereas a 2-day sample provides a fairly good representation of a typical day, a 1day sample does not. Similarly, the correlation between the two sets of estimates of fathers' taking sole responsibility was only $r$ $=.22$, probably reflecting the lack of representativeness of a 2 days' sampling for a behavior that occurs with a very low frequency (see below). Except for these two measures, the more robust time-use-based measures were sufficiently similar to the paternal questionnaire estimates to provide evidence for the latter's overall validity. Because the involvement estimates obtained from the two sources were not only highly correlated as a rule but also very close in absolute values, and because instances of discrepancies could be reasonably attributed to the weakness of the day-sampling method, it was decided to rely solely on the questionnaire data for further analysis.

Parental beliefs.-Both parents' beliefs concerning the timetable of infants' cognitive development and the best time for introduction of cognitively enriching experiences were obtained through a questionnaire consisting of 21 items. These items are listed in Table 2, grouped by domain (capacities or activities), and in an ascending order according to the average age estimated by mothers; in the questionnaire itself, the order of the different items was randomized as to domain and expected age. The questions referred to infants in general rather than to the subjects' own children (e.g., "At what age, in your opinion, do babies begin to understand words?" "At what age do you think it is best to start explaining to babies what they see in a picture-book?"). This questionnaire is a modification of the one used by Ninio (1979) and consists of items that formed the "cognitive cluster" in that study.

Parents were interviewed at their home. The two parents were interviewed simultaneously, in separate rooms. Mothers were interviewed only regarding their beliefs but not about fathers' involvement in infant care. The interviews were conducted by eight trained psychology students working in pairs.

\section{Results}

\section{Parental Involvement}

Data concerning daily average involvement of the fathers in the care of their infants are shown in Table 1; to permit comparison of these data to previous findings, many of which were restricted to fathers of firstborns, the results for first- and later-borns are presented separately.

As seen in Table 1, the average father in this sample was available to his 9-month-old infant for about 2.75 hours on a weekday (range from 0 to $360 \mathrm{~min}$ ) and spent about 45 min in active interaction with the child (range from 0 to $210 \mathrm{~min}$ ). Thus, on the average, fathers are using for interaction about $30 \%$ of the time available for it. Fathers of firstborns spent more time in interaction than fathers of later-borns (62.8 vs. $44.6 \mathrm{~min})$. The former 
TABLE 1

Daily Average Involvement of Fathers in the Care of Their INFANTS

\begin{tabular}{|c|c|c|c|c|c|c|}
\hline \multirow[b]{3}{*}{ MEASURES OF INVOLVEMENT } & \multicolumn{4}{|c|}{ FATHERS OF: } & & \\
\hline & \multicolumn{2}{|c|}{$\begin{array}{c}\text { Firstborns } \\
(N=43)\end{array}$} & \multicolumn{2}{|c|}{$\begin{array}{l}\text { Later-borns } \\
(N=117)\end{array}$} & \multicolumn{2}{|c|}{$\begin{array}{c}\text { TotaL } \\
(N=160)\end{array}$} \\
\hline & $M$ & SD & $M$ & SD & $M$ & SD \\
\hline Availability (min) & 169.8 & 85.0 & 161.8 & 73.5 & 164.0 & 76.6 \\
\hline Interaction $(\min ) \ldots \ldots$ & 62.8 & 38.9 & 44.6 & $34.9^{\mathrm{a}}$ & 45.1 & 32.0 \\
\hline \multicolumn{7}{|l|}{ Caretaking activities: } \\
\hline Total $\ldots \ldots \ldots \ldots$ & 1.09 & .92 & .99 & 1.00 & 1.01 & .98 \\
\hline Feeding $\ldots \ldots \ldots \ldots \ldots \ldots$ & .39 & .40 & .30 & .40 & .32 & .40 \\
\hline Dressing/diapering $\ldots \ldots \ldots \ldots$ & .28 & .37 & .25 & .36 & .26 & .36 \\
\hline Bathing ..................... & .10 & .23 & .10 & .23 & .10 & .23 \\
\hline Putting to bed $\ldots \ldots \ldots \ldots \ldots$ & .33 & .29 & .34 & .34 & .33 & .33 \\
\hline 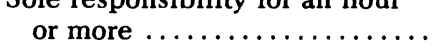 & .15 & .18 & .11 & .15 & .12 & .16 \\
\hline
\end{tabular}

a The difference between fathers of firstborns and later-borns was significant at $p<.01$.

used about $37 \%$ of the time for interaction, the latter only $27 \%$.

On the average, fathers performed one caretaking activity per day out of a possible 10 ; about $20 \%$ performed no such activities at all, and about $15 \%$ performed more than two a day (in the interview, $52.5 \%$ of the fathers reported performing no caretaking acts at all in the 2 weekdays sampled).

About half of the fathers $(45.6 \%)$ never took sole responsibility for their infants for a meaningful period of time (i.e., an hour or more while the infant is awake) within a typical 10-day period; $36.3 \%$ did so once or twice, $11.9 \%$ three or four times, and $6.2 \%$ five to eight times (by interview data, the daily average time alone with the infant was $8.8 \mathrm{~min}$, SD $=4.9$ ). Because fathers very seldom took sole responsibility for their infants, and the distribution of responsibility scores did not approximate the normal, this score was omitted from further analyses.

A MANOVA was carried out, with the three indices of involvement as withinsubjects repeated measures and child sex, birth order (first- vs. later-born), and mother's employment as the between-subjects factors. None of the multivariate tests for interaction were significant: sex $\times$ birth order $\times$ maternal employment, $F(3,138)=1.49$; sex $\times$ maternal employment, $F(3,138)=2.52$; birth order $\times$ maternal employment, $F(3,138)=$ 0.53 ; birth order $\times$ sex, $F(3,138)=0.10$, all $p>.05$, nor were the main effects of sex, $F(3,138)=0.51$, and maternal employment, $F(3,138)=1.43$, all $p>.05$. The multivariate test for the effect of birth order was significant, $F(3,138)=3.93, p<.01$. However, within-involvement-type a priori comparisons revealed that fathers of firstborns differed from fathers of later-borns only in interaction time, $F(1,140)=9.26, p<.01$, but not on the other two measures: availability, $F(1,140)=0.40$; caretaking, $F(1,140)=0.59$, both $p>.05$.

The correlations among the three involvement measures were $r(153)=.59$ (availability and interaction), $r(154)=.36$ (availability and caretaking), and $r(158)=.58$ (interaction and caretaking), all significant at the $p<.001$ level. The correlations for fathers of firstborns did not differ significantly from those of later-borns, or of fathers to girls from those of fathers to boys, or of husbands to employed mothers from those of husbands to unemployed ones. This pattern of correlations indicates that the various aspects of paternal involvement are only moderately linked.

Correlations between the three involvement measures and indexes of fathers' cultural background show only weak subcultural differentiation in involvement. Fathers with higher education were more available to their infants, $r(138)=.13, p<.05$, and took care of them more often, $r(143)=.20, p<.01$. Fathers who were born in Israel were also more available, $r(154)=.22, p<.01$. Ethnic origin (Western/non-Western) did not show any significant relations with the involvement indices.

\section{Attributions of Cognitive Competence to Infants by Fathers and Mothers}

The timetable of cognitive development and of caregiving activities as estimated by 
TABLE 2

Timetable of Cognitive Development and Caretaking ACtivities (in Months) Estimated by MOTHERS AND FATHERS OF 9-MONTH-OLD INFANTS $(N=160)$

\begin{tabular}{|c|c|c|c|c|}
\hline \multirow[b]{2}{*}{ VARIABLES } & \multicolumn{2}{|c|}{ MOTHERS } & \multicolumn{2}{|c|}{ FATHERS } \\
\hline & $M$ & SD & $M$ & SD \\
\hline \multicolumn{5}{|l|}{ Cognitive development: } \\
\hline \multicolumn{5}{|l|}{ Age at which infants start to: } \\
\hline See $\ldots \ldots \ldots \ldots \ldots \ldots \ldots$ & .66 & .69 & .96 & 1.00 \\
\hline Hear $\ldots \ldots \ldots \ldots \ldots \ldots \ldots$. & .76 & 1.22 & 1.12 & 1.40 \\
\hline Identify their mother's voice ....... & 2.94 & 2.15 & 3.48 & 2.30 \\
\hline \multicolumn{5}{|l|}{ Differentiate angry from joyful tone } \\
\hline of voice $\ldots \ldots \ldots \ldots \ldots \ldots \ldots \ldots$ & 3.65 & 2.50 & 4.38 & 3.18 \\
\hline Identify their mother $\ldots \ldots \ldots \ldots \ldots \ldots$ & 4.15 & 2.12 & 4.45 & 2.88 \\
\hline Identify their father .... & 5.51 & 2.25 & 6.29 & 4.49 \\
\hline Understand angry face .... & 6.18 & 2.93 & 8.24 & 6.28 \\
\hline Understand words ........ & 7.53 & 2.49 & 8.84 & 4.16 \\
\hline Miss their mother & 8.22 & 4.34 & 9.02 & 6.25 \\
\hline Say first words $\ldots \ldots \ldots \ldots \ldots \ldots \ldots$ & 8.77 & 2.95 & 9.95 & 3.49 \\
\hline \multicolumn{5}{|l|}{ Understand intention to go for walk } \\
\hline when taken to the door $\ldots \ldots \ldots \ldots \ldots$ & 8.84 & 3.72 & 9.94 & 5.58 \\
\hline Understand "no!" . ............ & 9.54 & 3.47 & 11.53 & 6.16 \\
\hline \multicolumn{5}{|l|}{ Distinguish small children and } \\
\hline adults $\ldots \ldots \ldots \ldots \ldots \ldots \ldots$ & 10.45 & 6.53 & 12.60 & 10.70 \\
\hline Identify pictures of objects $\ldots \ldots \ldots \ldots$ & 11.49 & 3.84 & 13.99 & 6.55 \\
\hline Be jealous of his/her siblings $\ldots \ldots \ldots \ldots$ & 14.59 & 8.10 & 15.78 & 9.13 \\
\hline \multicolumn{5}{|l|}{ Caregiving activities: } \\
\hline \multicolumn{5}{|l|}{ Age at which it is expedient to: } \\
\hline Start talking to baby $\ldots \ldots \ldots \ldots \ldots$ & .29 & 1.06 & 1.31 & 2.21 \\
\hline Let baby start to feed him/herself a & & & & \\
\hline piece of bread $\ldots \ldots \ldots \ldots \ldots \ldots$ & 6.85 & 2.71 & 8.96 & 6.15 \\
\hline Buy first picture-book $\ldots \ldots \ldots$ & 7.41 & 3.65 & 9.26 & 6.50 \\
\hline Teach baby not to touch fragile & & & & \\
\hline objects $\ldots \ldots \ldots \ldots \ldots \ldots \ldots$ & 9.39 & 4.07 & 10.82 & 6.48 \\
\hline Explain pictures in picture-books & 9.93 & 3.84 & 13.56 & 7.53 \\
\hline Start talking of absent objects $\ldots$. & 11.07 & 5.60 & 15.51 & 9.06 \\
\hline
\end{tabular}

the mothers and the fathers in our sample is shown in Table 2. Results of a repeatedmeasures MANOVA comparing mothers and fathers of the same infants over the 21 test items revealed that fathers consistently believe that infants acquire basic cognitive skills, and can participate in cognitively enriching or demanding activities, at a later age than do mothers, multivariate $F(1,159)=$ 798.05, $p<.001$.

As a group, fathers were also found to be more heterogeneous in their beliefs than mothers, as evidenced by the considerably larger variance of fathers' scores on all items; in all but one item ("identify their mother's voice"), the difference between the variances was significant by $F$ test at least at the .05 level.

In an effort at data reduction, principal component factor analyses were performed on the 21 items. The first factor accounted for $31.1 \%$ of the variance for mothers and $42.6 \%$ for fathers; in the combined mother and father group, it accounted for $40.6 \%$ of the variance. All 21 items had moderate (.30) to high (.80) loadings on the common factor in each analysis, and the configurations were similar. It appears that the first principal component represents a parent's general tendency to impute early versus late social-cognitive development to infants, which underlies his or her estimates of specific developmental milestones. Additional factors accounted for $10 \%$ or less of the variance and thus discourage further subcategorization of the 21 developmental milestone items.

For each parent, a mean developmental timetable score was computed by averaging their responses to the questionnaire items. This score, representing the mean age at which a parent believes infants achieve the 21 developmental milestones, is very highly correlated with factorial scores derived from the factor analysis described above (for mothers, $r=.99$; for fathers, $r=.97$ ) and thus 
may be considered a transformation on the factorial scores. The advantage of using the former is that, being expressed in terms of months, they are more clearly descriptive. ${ }^{1}$ Mothers' average timetable of overall achievement was 7.06 months $(\mathrm{SD}=1.92$ ), fathers' was $8.56(\mathrm{SD}=3.62)$. The paired difference was significant, $t(159)=-6.08, p<$ .001 . Additionally, the variance of the fathers' scores was significantly higher, $F(159,159)=$ $3.73, p<.001$.

Mothers' cultural background had a low but significant relation with their beliefs. The correlation coefficients were $r(132)=.15$ with ethnicity, $r(159)=.16$ with birthplace, and $r(159)=.21$ with education, all significant at least at $p<.05$. Similar results were obtained for fathers: their beliefs were significantly correlated with their ethnic origin, $r(143)=.24, p<.01$, and education, $r(158)=$ $.30, p<.001$, although not with their birthplace, $r(159)=.09$.

\section{Relations between Paternal Involvement and Attributions of Cognitive Competence to Infants}

Pearson correlations were computed between fathers' developmental timetable scores and the availability, interaction, and caretaking indices of their involvement in infant care. The correlation coefficients were $r(134)=-.17, p<.05$, for availability; $r(134)$ $=-.33, p<.001$, for interaction; and $r(134)$ $=-.24, p<.01$, for caretaking. Partialing out the effect of fathers' ethnic origin (Western/ non-Western), birthplace (Israeli/foreign born), and years of education did not affect these values to any significant degree; the partial correlations were $-.17,-.31$, and -.20 for availability, interaction, and caretaking, respectively, with $131 d f$ and the same significance levels as before. Comparison of the correlation coefficients between developmental timetable scores and the three involvement indices for fathers of male versus female infants and for husbands of employed versus unemployed mothers revealed no significant $(p<.05)$ differences: fathers of males, $r(72)=-.22, r(75)=-.23, r(76)=$ -.18 ; fathers of females, $r(81)=-.19, r(82)=$ $-.29, r(82)=-.26$; husbands of employed mothers, $r(88)=-.28, r(88)=-.24, r(88)=$ -.18 ; husbands of unemployed mothers, $r(59)$ $=-.15, r(63)=-.33, r(63)=-.36$, for availability, interaction and caretaking, re- spectively. Mothers' beliefs about the capacities of infants also had some relation with fathers' involvement, $r(152)=-.13, p>.05$, for availability, $r(156)=-.23, p<.01$, for interaction, and $r(157)=-.16, p<.05$, for caretaking. The two parents' developmental timetable scores were moderately correlated, $r(159)=.48, p<.001$. Inclusion of the maternal developmental timetable scores in stepwise multiple regression analyses alongside the paternal scores revealed that the former made no independent contributions to the prediction of fathers' availability, interaction time, or caretaking: in none of the three analyses did the maternal scores enter the stepwise multiple regression equation with a significant $(p<.05)$ contribution. It appears that there exists some relation between the degree to which fathers are involved in infant care, and especially the amount of time they spend interacting with their infants, and their attributions of social-cognitive competence to infants. Moreover, the partial correlations reported above indicate that this relation is independent of fathers' cultural background, as indexed by their ethnicity or degree of exposure to the Israeli society.

In order to ascertain whether fathers' availability to the infant and their performance of caretaking activities may contribute to the formation of positive attributions of infant competence, independent of effects contributed by experiences of interaction with the infant, partial correlations were computed between the former two and fathers' developmental timetable scores, controlling for amount of interaction. The resulting coefficients were $r(150)=-.03$ for availability and $r(155)=-.08$ for caretaking, neither of which is significant at $p=.05$. It appears that merely spending time in the proximity of the infant is not sufficient for learning about his or her abilities. Moreover, performing caretaking activities for the infant does not by itself help a father to modify his opinion of the infant, over and above contributing to total interaction time.

\section{Threshold Effects of Exposure on}

Attributions of Competence to Infants

In order to investigate the finer details of the relation between amount of interaction with the infant and fathers' attributions of cognitive competence to infants, a one-way ANOVA was carried out on mean develop-

\footnotetext{
${ }^{1}$ As a single principal-component solution was decided on, rotation was inappropriate, and the unrotated initial-factor-score coefficients were used for computing the factorial scores. These consisted of the weighted averages of the standardized values of the variables that had been factor analyzed and are expressed as deviations from a mean of zero.
} 
TABLE 3

Means and Standard Deviations of Fathers' Developmental Timetable SCORES AS a Function OF AMOUNT OF TIME SPENT IN INTERACTION WITH THE INFANT

\begin{tabular}{|c|c|c|c|c|}
\hline \multirow{2}{*}{$\begin{array}{l}\text { INTERACTION TIME } \\
\text { (Minutes) }\end{array}$} & \multicolumn{3}{|c|}{$\begin{array}{l}\text { DEVELOPMENTAL } \\
\text { TIMETABLE }\end{array}$} & \multirow{2}{*}{$\begin{array}{l}T \text { VALUE FOR CONTRAST } \\
\text { WITH NEXT GROUP }\end{array}$} \\
\hline & $N$ & $M$ & SD & \\
\hline$\ldots \ldots \ldots \ldots \ldots$ & 25 & 11.87 & 5.85 & $2.55^{*}$ \\
\hline $16-30 \ldots \ldots \ldots \ldots$ & 41 & 8.66 & 2.95 & 1.19 \\
\hline$\ldots \ldots \ldots \ldots \ldots$ & 25 & 7.93 & 2.03 & -.64 \\
\hline$\ldots \ldots \ldots \ldots \ldots$ & 22 & 8.43 & 3.11 & $2.06^{*}$ \\
\hline $61-75 \ldots \ldots \ldots \ldots$ & 20 & 6.76 & 2.08 & -.75 \\
\hline $76+\ldots \ldots \ldots \ldots \ldots$ & 27 & 7.38 & 2.34 & \\
\hline
\end{tabular}

mental timetable scores of fathers grouped by amount of interaction time expressed in units of $15 \mathrm{~min}$. The overall $F$ was highly significant, $F(5,154)=7.03, p<.001$. Means and standard deviations of the developmental timetable scores of each group, as well as the results of $t$ tests of a priori contrasts between each group and the one next to it, are shown in Table 3 (because the within-group variances differed, separate variance estimates were used).

The results indicate that fathers who spend only up to $15 \mathrm{~min}$ a day interacting with their infants attribute significantly less social-cognitive maturity to infants than fathers who spend more time with their child, even if that time is only between 16 and 30 min a day. The difference between the first two groups is not only significant but also surprisingly large: the extremely noninvolved fathers believe that infants pass the relevant developmental milestones more than 3 months later on the average than fathers who interact a bit more with their child. Attributions do not vary further with increasing in- teraction time until the threshold of $60 \mathrm{~min}$ is passed. When, however, fathers interact more than $60 \mathrm{~min}$ a day with their infants, their attributions are significantly more generous.

On the basis of these results, fathers were divided into three groups: extremely noninvolved (0-15 min of daily interaction), medium involved (16-60 min of daily interaction), and highly involved (more than $60 \mathrm{~min}$ of daily interaction). To establish whether fathers in the medium and high-involvement groups are closer to their wives in terms of attributions of competence to infants than fathers in the noninvolved group, a repeatedmeasures MANOVA was carried out on parents' developmental timetable scores, with parental sex as the repeated factor and paternal involvement group as the betweensubjects factor. The means and standard deviations of the six subgroups of parents, as well as the results of a priori contrasts between the matched pairs of parents within each involvement group, are shown in Table 4. There was a significant involvement group $\times$ parental sex interaction, $F(2,157)=9.33, p<.001$; the

TABLE 4

Means and Standard Deviations of Fathers' and Mothers' Developmental Timetable Scores by Categories of Paternal Interaction Time

\begin{tabular}{|c|c|c|c|c|c|c|}
\hline \multirow{3}{*}{$\begin{array}{l}\text { INTERACTION TIME } \\
\text { (Minutes) }\end{array}$} & \multirow[b]{3}{*}{$N$} & \multicolumn{4}{|c|}{$\begin{array}{l}\text { Developmental } \\
\text { Timetable Scores }\end{array}$} & \multirow{3}{*}{$\begin{array}{l}F \text { VALUE FOR CONTRAST } \\
\text { BETWEEN PARENTS }\end{array}$} \\
\hline & & \multicolumn{2}{|c|}{ Mothers } & \multicolumn{2}{|c|}{ Fathers } & \\
\hline & & $M$ & SD & $M$ & SD & \\
\hline $0-15 \ldots \ldots \ldots \ldots \ldots$ & 25 & 8.09 & 2.33 & 11.87 & 5.85 & $37.24^{* * *}$ \\
\hline $16-60 \ldots \ldots \ldots \ldots$ & 88 & 7.01 & 1.79 & 8.40 & 2.75 & $17.59^{* * *}$ \\
\hline $61+\ldots \ldots \ldots \ldots \ldots \ldots \ldots \ldots .6$. & 47 & 6.62 & 1.74 & 7.11 & 2.23 & 1.18 \\
\hline
\end{tabular}

$* * * p<.001$. 


\section{Child Development}

a priori contrasts revealed that the attributions of the highly involved fathers did not differ significantly from those of their wives, whereas the attributions of noninvolved and medium-involved fathers did.

\section{Discussion}

\section{Extent of Paternal Involvement in the Sample}

The fathers in this study exhibit, on the whole, a traditional style of fatherhood, comparable to that of unselected groups of fathers in the United States, England, France, and Australia. Our estimates of paternal availability and interaction time fall between the higher figures reported by Kotelchuck (1976), Masalcha (1982), Pedersen and Robson (1969), and Russell $(1980,1982,1983)$ and the lower estimates of Ban and Lewis (1974) and Pleck (1982). As in most studies, the variability in levels of paternal involvement is remarkable.

The findings regarding fathers' participation in caretaking point mainly to the irregular nature of this type of paternal involvement. Although in a typical 10-day period, including weekends, $80 \%$ of the sample reported performing at least one act of caretaking, this proportion is reduced to $47 \%$ for the 2 workdays sampled in the interview. These estimates are lower than those of Chai Am (1985), but higher than the ones given by Mouras (1985) and by Baruch and Barnett (1983). In the latter study, $71 \%$ of the fathers claimed to have no responsibility for everyday care. The lower estimates obtained by Baruch and Barnett (1983) and by Mouras (1985) can be partly accounted for by the older age of the children whose fathers they studied, who need less caretaking than infants.

There is agreement between the present study and those of others (see Kotelchuck, 1976; Mouras, 1985; Richards, Dunn, \& Antonis, 1977; and Russell, 1978) with regard to the relative frequency with which fathers engage in various caretaking activities. As Mouras (1985) has concluded, fathers participate more in activities that involve less physical contact.

Fathers in our sample were somewhat more likely to take sole responsibility for the infant than has been reported in previous studies. Compared to the $75 \%$ of the fathers in Kotelchuck's (1976) sample and the $60 \%$ in Russell's (1983) study, only $46 \%$ of the fathers in the present study did not take sole responsibility for their infants even once in 10 days.
However, the proportion of highly responsible fathers was very low: only about $6 \%$ of those participating in the current study took sole responsibility of the infant for more than an hour at least once in every 2 days.

The different involvement measures were found to be moderately interrelated, with correlations ranging from .36 to .59 . These correlations, as well as the differential correlations between these indices and the demographic variables, exhibit patterns that show a great similarity to the findings of Radin and Sagi (1982) with respect to preschoolers, and to those of Riley (1985). Thus, we concur with Riley's and with Lamb et al.'s (1985) conclusion that the different facets of paternal involvement are relatively independent.

As to the two methods of assessing fathers' involvement that were employed in this study, it appears that in spite of its a priori higher face validity, assessment through retrospective reports of time use had serious limitations. Two days are too small and atypical a sampling of fathers' overall pattern of behavior, especially with regard to infrequent activities such as taking sole responsibility for the infant. Increasing the number of days for which reports are obtained would probably have reduced the validity of the information because it is questionable whether fathers can reliably remember in detail what they did 3 or more days previously. A daily diary on time use may solve the memory problem, and if kept for 2 or 3 weeks, it could also insure generality; this, however, demands a relatively serious investment from the respondents. The much more easily obtainable direct estimates of involvement may be the next best approximation; in general, there was a remarkable similarity between these estimates and estimates derived from the timeuse reports in this study, except in instances where discrepancies could be expected to follow from the atypicality of the two sampled days. It is possible, though, that it is the conjunction of both methods that contributed to the validity of fathers' direct estimates: The indirect time-use reports were obtained first and the direct estimates of involvement immediately after, and the former may have helped fathers to give realistic estimates of their 10-day pattern.

\section{Relations between Paternal Involvement and Attributions of Cognitive Competence to Infants}

The results of this study are congruent with the hypothesis that there is a positive 
relation between degree of involvement in an infant's care and attributions of socialcognitive competence to infants. The hypothesis was confirmed on three counts: $(a)$ the more a father is involved in infant care, the higher are his opinions of infant capacities; (b) fathers attribute, on the average, less competence to infants than mothers; and (c) the difference between matched pairs of fathers and mothers decreases the more the fathers are involved in infant care; in the case of highly involved fathers, the difference between them and their wives is reduced to nonsignificance. Our analyses also indicate that the relation between involvement and attributions is not due to both variables being independently related to fathers' cultural background: although fathers' cultural background is in fact somewhat associated with degree of involvement as well as with attributions of competence, the relation between the latter two is not spuriously mediated by the former. Nor is this relation dependent on the infant's gender or the employment status of the mother. Other intervening variables that were not explored in this study may of course exist; however, it is not implausible to propose that the relation is in fact causal in that either a greater degree of involvement provides better opportunities for observing the emergence of competencies in infants, or that fathers with a higher opinion of infant capacities became more involved in their care. The present study does not allow choosing between these two interpretations. As noted earlier, the relation between involvement and attributions may be circular: believing that infants are relatively complex and thus interesting persons may serve to enhance a parent's readiness to take care of them and spend much time in their company; actual exposure may reinforce these beliefs and vice versa.

Assuming that some of the direction of effect is from involvement to attributions, the crucial variable for affecting fathers' opinions seems to lie in the amount of time spent in interaction with the infant. Merely spending time in the vicinity of the infant is not a sufficient condition for learning about his or her abilities; similarly, performing caretaking activities for the infant does not by itself help a father to modify his opinion of the infant, over and above the increase in interaction time.

Two thresholds for effects of interaction time were suggested by the results. Fathers who spend 15 min or less daily in interaction hold exceptionally low opinions on infant capacities, both in comparison to their wives and to other fathers. It is possible that such fathers minimize their contact with infants precisely because they perceive them as lacking in interest value. Even if so, the resultant lack of opportunity to observe the infant prevents the modification of these opinions. The second threshold emerged at around an hour of daily interaction. Fathers who pass this threshold have as high an opinion of infant capacities as the average mother. Once again, these fathers may have entered parenthood with an a priori better opinion of what infants are capable of, and these beliefs may have enhanced their willingness to interact extensively with their infants.

Although no developmental norms exist for most of the items included in the developmental timetable questionnaire, judging from the items on which objective information does exist-for instance, the age at which infants start to see or hear-the earlier developmental milestones attributed by highly involved parents are objectively the more correct. However, even if these differences in the attributions of competence did not reflect a disparity in knowledge about infants but merely a difference of beliefs about them, they would still be important as potential sources of variability in parental behavior. It is a fair expectation that parents' beliefs about the mental capacities of infants at a particular age, and their attitudes regarding the kind of activities appropriate for infants to engage in at particular ages, influence their actual behavior with the infants. A parent who, for instance, believes that it is not expedient to explain pictures in picture-books before the age of 14 months because only at that age do infants start to identify pictures of objects, will not tend to engage in this behavior with a 9month-old, whereas other parents, with a more generous estimate of a 9-month-old's capacities, will be more likely to do so. Thus, such developmental expectations could be self-fulfilling, in that exposing the infant to a cognitively richer diet of experiences is likely to enhance their developmental status (see Elardo, Bradley, \& Caldwell, 1975). This indeed may be one of the reasons for the better cognitive development observed in children of highly involved fathers (for a review, see Lamb, 1981). If this assumption is correct, further research would probably find that lowand medium-involved fathers engage less in cognitively stimulating activities with their infants than highly involved fathers, as has already been established to be the case for preschool children (Radin, 1981). 


\section{References}

Ban, P., \& Lewis, M. (1974). Mothers and fathers, girls and boys: Attachment behavior in the one-year-old. Merrill-Palmer Quarterly, 20, 195-204.

Baruch, G. K., \& Barnett, R. G. (1983). Correlates of fathers' participation in family work: A technical report (Working Paper No. 106). Wellesley, MA: Wellesley College Center for Research on Women.

Baruch, G. K., \& Barnett, R. G. (1984, April). Fathers' participation in family work: Patterns, determinants and consequences. Paper presented at the Second International Interdisciplinary Congress on Women, Groningen, the Netherlands.

Bar-Yosef, R. (1969). Role differentiation in urban families in Israel. In R. Bar-Yosef \& I. Shelach (Eds.), The family in Israel (pp. 167-184). Jerusalem: Academon.

Chai Am, S. (1985). Attitudes towards the parental role during infancy amongst Israeli fathers and mothers of North-African origin. Unpublished M.A. thesis, The Hebrew University of Jerusalem.

Clarke-Stewart, K. A. (1978). And Daddy makes three: The father's impact on mother and young child. Child Development, 49, 466-478.

Elardo, R., Bradley, R., \& Caldwell, B. (1975). The relation of infants' home environments to mental test performance from six to thirty-six months: A longitudinal analysis. Child Development, 46, 71-76.

Goodnow, J. J., Cashmore, J., Cotton, S., \& Knight, R. (1984). Mothers' developmental timetables in two cultural groups. International Journal of Psychology, 19, 193-205.

Hoffman, L. W., \& Lippit, R. (1960). The measurement of family life variables. In P. H. Mussen (Ed.), Handbook of research methods in child development (pp. 945-1013). New York: Wiley.

Jackson, B. (1980). Towards a sketch of the CHES father. Unpublished manuscript.

Kotelchuck, M. (1976). The infant's relationship to the father: Experimental evidence. In $\mathbf{M}$. Lamb (Ed.), The role of the father in child development (pp. 329-344). New York: Wiley.

Lamb, M. E. (1976). Interactions between 8-monthold children and their fathers and mothers. In M. E. Lamb (Ed.), The role of the father in child development (pp. 307-327). New York: Wiley.

Lamb, M. E. (1981). Fathers and child development: An integrative overview. In M. E. Lamb (Ed.), The role of the father in child development (pp. 1-70). New York: Wiley.

Lamb, M. E., Pleck, J. H., Charnov, E. L., \& Levine, J. A. (1985). Paternal behaviour in humans. American Zoologist, 25, 883-894.
Lynn, D. B. (1974). The father: His role in child development. Monterey, CA: Brooks-Cole.

Masalcha, S. (1982). Parent-child relationship in the Arabic society in Israel. Unpublished M.A. thesis, The Hebrew University of Jerusalem.

Mouras, J. P. (1985, July). An attempt to operationalize the notion of "fathering." Paper presented at the Eighth Biennial Meeting of the International Society for the Study of Behavioral Development, Tours, France.

Ninio, A. (1979). The naive theory of the infant and other maternal attitudes in two subgroups in Israel. Child Development, 50, 976-980.

Oakley, A. (1974). The sociology of housework. London: Martin Robertson.

Palgi, P. (1970). The adaptability and vulnerability of family types in the changing Israeli society. In A. Jarus (Ed.), Children and families in Israel (pp. 97-135). New York: Gordon \& Breach.

Parke, R. D., \& Tinsley, B. R. (1981). The father's role in infancy: Determinants of involvement in caregiving and play. In M. E. Lamb (Ed.), The role of the father in child development (pp. 429-457). New York: Wiley.

Pedersen, F. A., \& Robson, K. S. (1969). Father participation in infancy. American Journal of Orthopsychiatry, 39, 466-472.

Pleck, J. H. (1982). Husbands' and wives' paid work, family work and adjustment. Wellesley, MA: Wellesley College Center for Research on Women.

Pleck, J. H. (1983). Husbands' paid work and family roles: Current research issues. In H. Lopata \& J. H. Pleck (Eds.), Research in the interweave of social roles. Vol. 3: Families and jobs (pp. 251-333). Greenwich, CT: JAI.

Power, T. G. (1985). Mother- and father-infant play: A developmental analysis. Child Development, 56, 1514-1624.

Radin, N. (1981). Childrearing fathers in intact families. I: Some antecedents and consequences. Merrill-Palmer Quarterly, 27, 489514.

Radin, N. (1982). Role-sharing fathers and preschoolers. In M. E. Lamb (Ed.), Nontraditional families: Parenting and child development ( $\mathrm{pp}$. 173-204). Hillsdale, NJ: Erlbaum.

Radin, N., \& Sagi, A. (1982). Childrearing fathers in intact families. II: Israel and the USA. MerrillPalmer Quarterly, 28, 111-136.

Richards, M. P. M., Dunn, J. F., \& Antonis, B. (1977). Caretaking in the first year of life: The role of fathers' and mothers' social isolation. Child: Care, Health and Development, 3, 2326.

Riley, D. (1985, April). Survey measurement of father involvement in childrearing: A reliability and validity study. Paper presented at the 
Biennial Meeting of the Society for Research in Child Development, Toronto.

Rosenthal, D. (1985, July). Child-rearing and cultural values: A study of Greek and Australian mothers. Paper presented at the Eighth Biennial Meeting of the International Society for the Study of Behavioral Development, Tours, France.

Russell, G. (1978). The father role and its relation to masculinity, femininity, and androgyny. Child Development, 49, 1174-1181.

Russell, G. (1979). The roles of fathers in child development-an Australian perspective. Paper presented to the 15th National Conference of the Australian Preschool Association, Sydney.

Russell, G. (1980, July). Fathers as caregivers: Possible antecedents and consequences. Paper presented to a study group on "Fathers and Social Policy," University of Haifa, Israel.

Russell, G. (1981). A multivariate analysis of fathers' participation in child care and play. Unpublished manuscript.

Russell, G. (1982). Shared-caregiving families: An Australian study. In M. E. Lamb (Ed.), Nontraditional families: Parenting and child development (pp. 139-172). Hillsdale, NJ: Erlbaum.

Russell, G. (1983). The changing role of fathers? St. Lucia: University of Queensland Press.

Sagi, A., \& Reshef, R. (1984). Parental expectations and aspirations and fathers' involvement in the care of their child within the two-parent family. Megamot, 28, 542-555.

Sigel, I. E., Hoffman, M. L., Dreyer, A. S., \& Torgoff, I. (1957). Influence techniques used by parents to modify the behavior of children: A case presentation. American Journal of Orthopsychiatry, 27, 356-364.

Wolfensbuerger, W., \& Kurtz, R. A. (1971). Measurement of parents' perceptions of their children's development. Genetic Psychology Monographs, 83, 3-92. 
http://www.jstor.org

\title{
LINKED CITATIONS
}

\author{
- Page 1 of 2 -
}

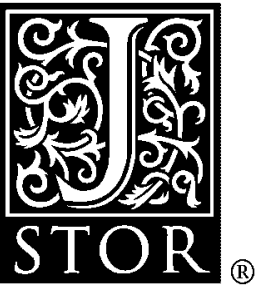

You have printed the following article:

Fathers' Involvement in the Care of Their Infants and Their Attributions of Cognitive Competence to Infants

Anat Ninio; Nurith Rinott

Child Development, Vol. 59, No. 3. (Jun., 1988), pp. 652-663.

Stable URL:

http://links.jstor.org/sici?sici=0009-3920\%28198806\%2959\%3A3\%3C652\%3AFIITCO\%3E2.0.CO\%3B2-\%23

This article references the following linked citations. If you are trying to access articles from an off-campus location, you may be required to first logon via your library web site to access JSTOR. Please visit your library's website or contact a librarian to learn about options for remote access to JSTOR.

\section{References}

\author{
And Daddy Makes Three: The Father's Impact on Mother and Young Child \\ K. Alison Clarke-Stewart \\ Child Development, Vol. 49, No. 2. (Jun., 1978), pp. 466-478. \\ Stable URL: \\ http://links.jstor.org/sici?sici=0009-3920\%28197806\%2949\%3A2\%3C466\%3AADMTTF\%3E2.0.CO\%3B2-P
}

\author{
The Relation of Infants' Home Environments to Mental Test Performance from Six to \\ Thirty-Six Months: A Longitudinal Analysis \\ Richard Elardo; Robert Bradley; Bettye M. Caldwell \\ Child Development, Vol. 46, No. 1. (Mar., 1975), pp. 71-76. \\ Stable URL: \\ http://links.jstor.org/sici?sici=0009-3920\%28197503\%2946\%3A1\%3C71\%3ATROIHE\%3E2.0.CO\%3B2-L \\ The Naive Theory of the Infant and Other Maternal Attitudes in Two Subgroups in Israel \\ Anat Ninio \\ Child Development, Vol. 50, No. 4. (Dec., 1979), pp. 976-980. \\ Stable URL: \\ http://links.jstor.org/sici?sici=0009-3920\%28197912\%2950\%3A4\%3C976\%3ATNTOTI\%3E2.0.CO\%3B2-G
}


http://www.jstor.org

\section{LINKED CITATIONS \\ - Page 2 of 2 -}

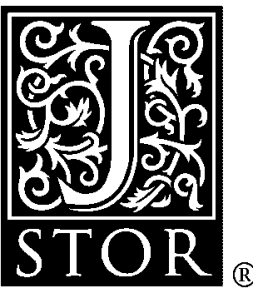

Mother- and Father-Infant Play: A Developmental Analysis

Thomas G. Power

Child Development, Vol. 56, No. 6. (Dec., 1985), pp. 1514-1524.

Stable URL:

http://links.jstor.org/sici?sici=0009-3920\%28198512\%2956\%3A6\%3C1514\%3AMAFPAD\%3E2.0.CO\%3B2-Q

The Father Role and Its Relation to Masculinity, Femininity, and Androgyny

Graeme Russell

Child Development, Vol. 49, No. 4. (Dec., 1978), pp. 1174-1181.

Stable URL:

http://links.jstor.org/sici?sici=0009-3920\%28197812\%2949\%3A4\%3C1174\%3ATFRAIR\%3E2.0.CO\%3B2-8 